Check for updates

Cite this: RSC Adv., 2019, 9, 27789

\title{
Combining a ligand photogenerator and a Ru precatalyst: a photoinduced approach to cross- linked ROMP polymer films $\uparrow$
}

\author{
Thi Kim Hoang Trinh, ${ }^{\text {ab }}$ Gautier Schrodj, ${ }^{\text {ab }}$ Séverinne Rigolet, ${ }^{\text {ab }}$ Julien Pinaud, (D) $^{c}$ \\ Patrick Lacroix-Desmazes, (D) ${ }^{c}$ Loic Pichavant, (D) ${ }^{d}$ Valérie Héroguez (D) ${ }^{d}$ \\ and Abraham Chemtob (iD *ab
}

\begin{abstract}
Although metathesis photoinduced catalysis is now well established, there is little development in thin film preparation using photochemically activated ring-opening metathesis polymerization (ROMP). Herein, a Nheterocyclic carbene $(\mathrm{NHC})$ photogenerator (1,3-bis(mesityl)imidazolium tetraphenylborate) is combined with an inactive metathesis catalyst $\left(\left[\mathrm{RuCl}_{2}(p \text {-cymene) }]_{2}\right)\right.$ to generate under UV irradiation an active catalyst ( $p$-cymene) $\mathrm{RuCl}_{2}(\mathrm{NHC})$, that is capable of producing in a single step cross-linked copolymer films by ROMP of norbornene with dicyclopentadiene. The study shows that the photoinitiated catalytic system can be optimized by increasing the yield of photogenerated NHC through a sensitizer (2isopropylthioxanthone), and by choosing $\left[\mathrm{RuI}_{2}(p \text {-cymene })\right]_{2}$ as precatalyst to provide a long-term photolatency. The cross-linked polymer structure is investigated by a range of techniques including gel content measurement, FT-IR and solid-state ${ }^{13} \mathrm{C}$ NMR spectroscopy, TGA and DSC, which reveal a cross-linking mechanism proceeding through both metathesis and olefin coupling.
\end{abstract}

Received 27th July 2019
Accepted 21st August 2019

DOI: 10.1039/c9ra05831a

rsc.li/rsc-advances

responded more to the needs of synthetic chemistry (as the above mentioned examples show), but have been less useful for the preparation of polymer materials. Ring-opening metathesis polymerization (ROMP) of cyclic olefins is currently the main type of olefin metathesis polymerizations. ${ }^{6,9}$ Polymers with a broad spectrum of properties have been achieved through ROMP of norbornene (NB), cyclopentene, cyclooctene or dicyclopentadiene (DCPD). However, the use of ROMP polymers has been limited so far to the manufacturing of specific structural and engineering materials. For example, polycyclooctene (Vestenamer®) and polyNB (Norsorex®) elastomers are employed after vulcanization as shock absorbers and anti-grip materials. In addition, hydrogenated polyNB (Zeonex®) is a high performance optical thermoplastic, while polyDCPD (Metton ${ }^{\circledR}$ or Telene ${ }^{\circledR}$ ) is known as a prime thermoset with mechanical properties similar to engineering thermoplastics. ${ }^{10}$ One reason for the limited applications of these polymers can be found in their restrictive processing methods. For example, polyDCPD is prepared essentially by reaction injection molding (RIM), which requires separate monomer and catalyst compartments, efficient mixing and titration heads, nitrogen inerting of the mold, etc. ${ }^{11-13}$

To unlock the potential of ROMP polymer materials, more efficient and "smarter" catalysts are crucial, especially to extend the shaping of ROMP polymers as film, particle or fiber, but also, to foster more versatile, energy-efficient and facile process conditions. $^{14-20}$ To address those challenges, latent olefin metathesis catalysts have emerged that are able to release active 
species in situ and "on demand" by external stimulation. Heat, ${ }^{14-16}$ mechanical force, ${ }^{17}$ and radiation ${ }^{\mathbf{1 8 - 2 0}}$ are the most common stimuli. A separate category concerns catalysts activated after the addition of an external chemical agent. ${ }^{21-23}$ Among these different options, the activation brought about by visible or ultraviolet irradiation is particularly attractive. ${ }^{24}$ Firstly, it allows activation of the catalyst at ambient temperature, and the use of storable and ready-to-use formulations combining together the catalyst and the monomer(s). Secondly, as a standard product of a photoactivated polymerization, thin films based on cross-linked ROMP polymer make possible the development of novel UV-curable coatings or adhesives. Thirdly, unlike the other triggers, light allows the reaction to be spatially-controlled, opening the way to applications in photolithography. ${ }^{23,25}$

In the field of photochemically activated olefin metathesis, three main approaches have been proposed to promote activation of the catalyst that all involve the photochemical reaction of one ligand of a transition metal complex. ${ }^{13}$ The two most reported routes rely on ligand photodissociation ${ }^{26,27}$ and ligand cis-to-trans photoisomerization. ${ }^{\mathbf{1 8 2 0}}$ The third route, which is the least investigated, is the focus of the present study. In the latter, the active olefin metathesis catalyst is produced from an inactive and non-absorbing precatalyst after reaction with a ligand generated in situ by a second photosensitive compound (ligand photogenerator). This methodology was first introduced by Grubbs et al. in 2009 by using a Ru-alkylidene complex ligated by acetylacetonate (acac) as precatalyst and a photoacid generator (PAG) based on triphenylsulfonium chloride. ${ }^{21}$ Upon irradiation at $254 \mathrm{~nm}, \mathrm{HCl}$ was released, and the subsequent displacement of acac by $\mathrm{Cl}^{-}$resulted in an active metathesis catalyst. A similar method was also employed by Piers et al. using a ruthenium carbide and $\mathrm{Ph}_{3} \mathrm{~S}$ triflate (OTf). ${ }^{22}$ Recently, we replaced the PAG with a NHC photogenerator and used a stable, commercially available dimeric $\mathrm{Ru}(\mathrm{II})$ complex as metathesis inactive catalyst (Scheme 1). ${ }^{\mathbf{2 8 , 2 9}}$ Our tandem system made up of 1,3-bis(mesityl)imidazolium tetraphenylborate $\mathrm{IMesH}^{+} \mathrm{BPh}_{4}{ }^{-}(\mathbf{1})$ as NHC progenitor and $\left[\mathrm{RuCl}_{2}(p \text {-cymene })\right]_{2}$ precatalyst (Ru-1) proved to be very efficient at ROMP of NB. In comparison with the examples discussed above, a safer UVA radiation (320-400 $\mathrm{nm}$ ) was employed, and no ligand displacement occurred. The cleavage of the $\mathrm{Ru}$-chlorido bridges of Ru-1 was rather enthalpically driven through the addition of 2 equivalents of free NHC IMes, that were photogenerated in situ from 1. As a result, the presumed active catalyst (Ru-1-IMes) features one $p$-cymene cycle, two chlorido ligands and one IMes ligand. First introduced by Hermann et al. ${ }^{30}$ this class of $\mathrm{RuCl}_{2}$ ( $p$-cymene)NHC catalyst has been extensively studied by Noels et al. for the ROMP of NB and cyclooctene. ${ }^{31-33}$

In this contribution, the main objective is to demonstrate the utility of this tandem approach for the photoinduced preparation of cross-linked ROMP polymer films. To this purpose, we report first our efforts to improve the photocatalytic system by addressing a number of issues: optimizing the yield of photogenerated IMes, ensuring a long-term photolatency, identifying the active metathesis catalyst and the initiating species, and finally, collecting some preliminary results on photoROMP in solution of common cyclic olefin monomers such as NB. In a second part, a range of copolymer films was prepared by photoinduced ROMP copolymerization between NB and DCPD using the photocatalytic mixture based on 1/ITX/Ru-1. The coatings were prepared in a single step from a one-pot formulation, which is close to the conditions of a conventional UVcuring process. The cross-linked copolymer structure was thoroughly investigated by gel content measurement, FT-IR and solid-state ${ }^{13} \mathrm{C}$ NMR spectroscopy. The thermal properties of these polymer films were also studied through TGA and DSC.

\section{Experimental}

\section{Materials}

Dicyclopentadiene (DCPD, >97\%, TCI), 2-norbornene (NB, $>99 \%$, TCI), 5-ethylidene-2-norbornene (ENB, >98\%, TCI), vinyl ethyl ether (>98\%, TCI), 2-isopropylthioxanthone (ITX, analytical standard, Aldrich), 1,3-bis(2,4,6-trimethylphenyl)imidazol2-ylidene (IMes, 97\%, Aldrich) and 1,3-di-p-tolylcarbodiimide (CDI, 96\%, Aldrich) were used as received without purification. 1,3-bis(2,4,6-trimethylphenyl)imidazolium tetraphenylborate

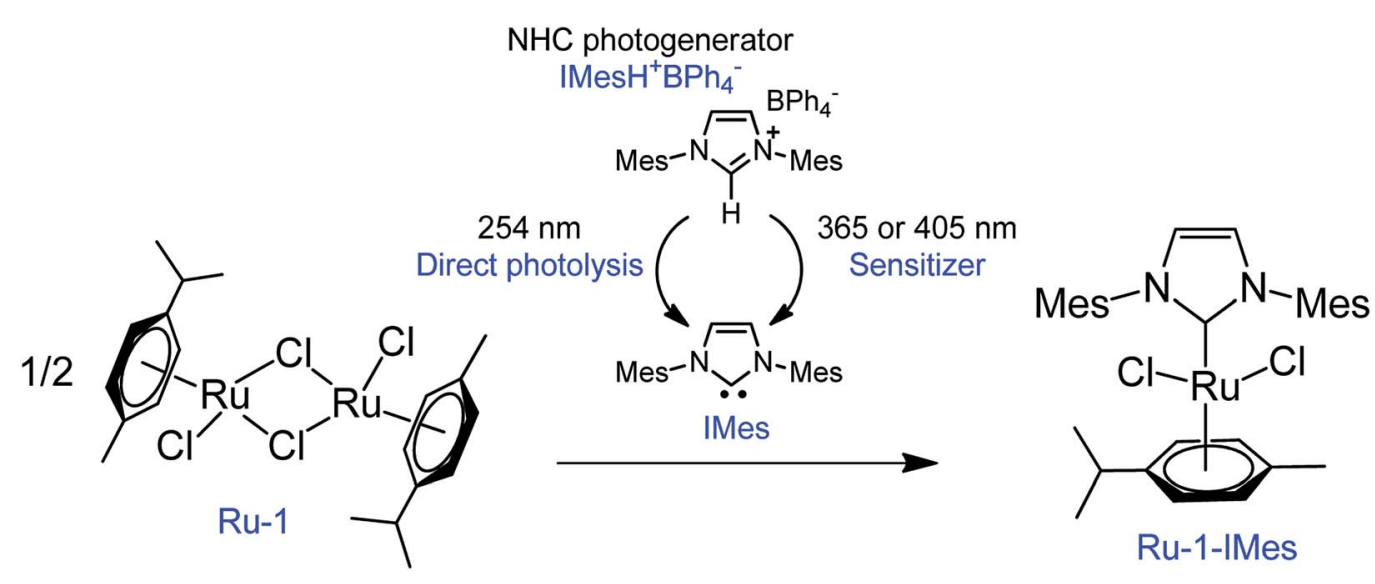

Scheme 1 A mixture of $\mathrm{NHC}$ photogenerator $\left(\mathrm{IMesH}^{+} \mathrm{BPh}_{4}{ }^{-}, 1\right)$ and an inactive dimeric Ru(॥) complex (Ru-1) results after irradiation in an active olefin metathesis photocatalyst (Ru-1-IMes). The NHC (IMes) can be photogenerated through two distinct routes: direct photolysis or sensitized reaction using an electronically excited electron acceptor (sensitizer). 
$\left(\mathrm{IMesH}^{+} \mathrm{BPh}_{4}{ }^{-}, \mathbf{1}\right)$ was prepared following a procedure published elsewhere. ${ }^{28}$ Dichloro( $p$-cymene)ruthenium(II) dimer (Ru-1, 98\%), diiodo(p-cymene)ruthenium(II) dimer (Ru-2, 98\%) and dichlorodi- $\mu$-chlorobis[1,2,3,6,7,8-ๆ-2,7-dimethyl-2,6-octadiene-1,8-diyl] diruthenium(Iv) (Ru-3, 98\%) were bought from Strem Chemicals. Dichloromethane- $d_{2}\left(\mathrm{CD}_{2} \mathrm{Cl}_{2}, 99.5 \% \mathrm{D}\right.$, Eurisotop), tetrahydrofuran- $d_{8}$ (THF- $d_{8}, 99.5 \%$ D, Eurisotop) and other HPLC grade solvents such as ethanol, acetonitrile and tetrahydrofuran (THF) received from VWR were distilled and stored over molecular sieve (4 Å) under nitrogen atmosphere before use.

\section{Syntheses and procedures}

Quantification of IMes yield. Quantitative conversion of IMes into IMes-carbodiimide (CDI) adduct was described elsewhere. ${ }^{29}$ The irradiation sources include a medium pressure XeHg lamp (75 $\mathrm{mW} \mathrm{cm}{ }^{-2}$, Hamamatsu, LC-9588/01A), a LED@365 nm (65 mW cm ${ }^{-2}$, Hammamatsu LC-L1V3) and a LED@405 nm (100 mW cm ${ }^{-2}$, Thorlabs M405L2). The irradiances were determined by using an optical power meter PM100D from Thorlabs.

Assessment of catalyst photolatency. In a typical experiment, NB ( $47 \mathrm{mg}, 510$ equiv.), ITX ( $0.63 \mathrm{mg}, 2.5$ equiv.) and ruthenium pre-catalyst Ru-1 $(0.62 \mathrm{mg}, 1$ equiv.) were placed in a borosilicate NMR tube containing $0.5 \mathrm{~mL}$ of $\mathrm{CD}_{2} \mathrm{Cl}_{2}$. All solutions were stored in dark. After a fixed time, a ${ }^{1} \mathrm{H}-\mathrm{NMR}$ spectrum was recorded to determine the extent of monomer conversion and cis/trans ratio of the polymer possibly formed.

Photoactivated ROMP in solution. To a borosilicate NMR tube was added $47 \mathrm{mg}$ of NB (510 equiv.), $0.63 \mathrm{mg}$ of ITX (2.5 equiv.), $3 \mathrm{mg}$ of 1 (5 equiv.), $0.62 \mathrm{mg}$ of Ru-1 (1 equiv.), then $0.5 \mathrm{~mL}$ of $\mathrm{CD}_{2} \mathrm{Cl}_{2}$. The solutions were irradiated in a circular LED photoreactor. For this, a LED strip was wrapped around a quartz cylinder $\left(\phi_{\text {int }}=60 \mathrm{~mm}\right)$ emitting a monochromatic light centered at $365 \mathrm{~nm}$ (SMD3528-60LED/Meter, Lightingwill, $6.5 \mathrm{~mW} \mathrm{~cm}^{-2}$ ) or $405 \mathrm{~nm}$ (SMD2835-60LED/Meter, Banggood, $4.7 \mathrm{~mW} \mathrm{~cm}{ }^{-2}$ ). After $1 \mathrm{~min}$ irradiation, ${ }^{1} \mathrm{H}$-NMR spectra were recorded to determine monomer conversion and cis/trans ratio. Excess amount of vinyl ethyl ether $(0.1 \mathrm{~mL})$ was added to terminate the polymerization. Polymers were collected through precipitation in acetone and washed 3 times with $\mathrm{CH}_{2} \mathrm{Cl}_{2}$ / acetone. SEC measurements were performed after drying under air for $48 \mathrm{~h}$. For measurements of real-time kinetics by RT-FTIR (see characterization section), the same NB/ITX/1/Ru-1 mixture was introduced into an IR liquid cell (Specac ${ }^{\circledR}$ Omni cell) containing two sandwich $\mathrm{CaF}_{2}$ windows. A $1 \mathrm{~mm}$ Teflon spacer in the middle of pellets was used to fix the specimen thickness. Samples were then exposed synchronously to an IR beam and an UV irradiation resource equipped with a light guide. Two types of LED were used: a LED@365 nm and a LED@405 nm (see above for details).

Preparation of cross-linked ROMP polymer films. A mixture of NB and DPCD was prepared at different NB concentrations ranging from 25 to $75 \mathrm{~mol} \%$. Ru-1 ( $9 \mathrm{mg}, 1$ equiv.), ITX (9.3 mg, 2.5 equiv.) and 1 ( $45 \mathrm{mg}, 5$ equiv.) were first dissolved in $\mathrm{CH}_{2} \mathrm{Cl}_{2}$ $(2 \mathrm{~mL}$ ), then the monomer mixture (510 equiv.) was added and left 10 min under stirring to obtain a homogeneous solution.
The mixture was then poured into a Teflon mold $(20 \times 85 \times$ $0.35 \mathrm{~mm}$ ) covered with a borosilicate glass plate. Clamps were used to maintain the glass plate in order to prevent air entry as well as evaporation of solvent and monomers. The weight of mold containing the reactive mixture was determined before irradiation to be used subsequently for gravimetry measurements. The mold was placed under a LED panel $(365 \mathrm{~nm}, 5.5$ $\mathrm{mW} \mathrm{cm}{ }^{-2}$, Top UV Curing Light) for $1 \mathrm{~h}$. The wet gel was removed from the mold and left to dry overnight at ambient atmosphere. Residual monomers and solvent were removed by drying under vacuum at $50{ }^{\circ} \mathrm{C}$ until the film reached a constant weight. The films exhibited an average film thickness of 0.25 $\mathrm{mm}$.

\section{Characterization methods}

All ${ }^{1} \mathrm{H}$-NMR spectra were recorded in appropriate deuterated solvents with tetramethylsilane (TMS) as the internal reference on a Varian 300. All chemical resonances were documented in parts per million (ppm) relative to the residual THF- $d_{8}(\delta$ $1.72 \mathrm{ppm}$ and $3.58 \mathrm{ppm})$, and $\mathrm{CD}_{2} \mathrm{Cl}_{2}(\delta 5.32 \mathrm{ppm})$. Peaks multiplicities in ${ }^{1} \mathrm{H}-\mathrm{NMR}$ spectra were abbreviated as s (single), $\mathrm{d}$ (double), $\mathrm{t}$ (triplet), $\mathrm{m}$ (multiplet), br (broad).

Molecular weights of polyNB and polyENB were determined using a size exclusion chromatography (SEC) instrument from a Varian apparatus equipped with TOSOHAAS TSK gel columns and a refractive index detector. The mobile phase was THF at a flow rate of $1 \mathrm{~mL} \mathrm{~min}{ }^{-1}$; the injected volume was $100 \mu \mathrm{L}$. The MALS instrument was normalized using a THF solution of polystyrene standard.

Thermogravimetric analysis (TGA) and differential scanning calorimetry (DSC) experiments were performed using, respectively, a TGA/DSC3+ (Metter Toledo) and a DSC1 (Metter Toledo) under nitrogen atmosphere. For TGA analysis, the samples (8$15 \mathrm{mg}$ ) were heated from $30{ }^{\circ} \mathrm{C}$ to $600{ }^{\circ} \mathrm{C}$ at a heating rate of $10^{\circ} \mathrm{C} \mathrm{min}^{-1}$. For DSC analysis, the samples $(3 \mathrm{mg})$ were scanned from $-80^{\circ} \mathrm{C}$ to $250^{\circ} \mathrm{C}$ at a heating rate of $10^{\circ} \mathrm{C} \mathrm{min}{ }^{-1}$. The glass transition temperatures were determined in the second run.

To determine gel content, a polymer specimen $(\sim 50 \mathrm{mg})$ was placed into a $5 \mathrm{~mL}$ vial containing $4 \mathrm{~mL}$ of $\mathrm{CH}_{2} \mathrm{Cl}_{2}$. After magnetic stirring for $24 \mathrm{~h}$ at room temperature, the solvent was removed and insoluble component was dried under vacuum at $40{ }^{\circ} \mathrm{C}$ until weight constant. The gel content was finally measured.

${ }^{13} \mathrm{C}$ CP MAS NMR spectra were recorded by using an Advance II $400 \mathrm{MHz}$ Bruker Spectrometer (Ascend ${ }^{\mathrm{TM}}$ magnet) $\left(B_{0}=9.4 \mathrm{~T}\right.$ ) operating at $100.64 \mathrm{MHz}$ and controlled by TOPSPIN 3.2 software. The solid films were grounded into fine powders prior to measurement. Experiments were performed at ambient temperature with a $4 \mathrm{~mm}$ double resonance MAS Bruker probe at a speed of $12 \mathrm{kHz}, \mathrm{a}^{13} \mathrm{C} \pi / 2$ pulse duration of $5.6 \mu \mathrm{s}$, a contact time of $1 \mathrm{~ms}$ and a recycle delay of $2 \mathrm{~s}$. Chemical shifts reported thereafter are relative to tetramethylsilane and the deconvolution of the experimental spectra were carried out with the DMfit software. ${ }^{34}$ The fraction of pendant cyclopentene rings involved in olefin coupling reaction can be determined semiquantitatively from the ${ }^{13} \mathrm{C}$ CP MAS NMR spectrum. DCPD 
contains initially $4 \mathrm{sp}^{2}$ and $6 \mathrm{sp}^{3}$ carbons. The ratio of $\mathrm{sp}^{2}$-C to $\mathrm{sp}^{3}$-C does not change when cyclopentene reacts by ROMP. Conversely, olefin coupling leads to the replacement of $2 \mathrm{sp}^{2}-\mathrm{C}$ by $2 \mathrm{sp}^{3}-\mathrm{C}$. This change can be used to estimate the fraction of cyclopentene reacting via olefin coupling $(x)$ in polyDCPD film (eqn (1)): $:^{35}$

$$
\frac{I_{\mathrm{s}^{2}-\mathrm{C}}}{I_{\mathrm{sp}^{3}-\mathrm{C}}}=\frac{4-2 x}{6+2 x}=\frac{2-x}{3+x}
$$

where $I_{\mathrm{sp}^{2}-\mathrm{C}}$ and $I_{\mathrm{sp}^{3}-\mathrm{C}}$ are the integrated areas of the signals associated to olefinic carbons (125-130 ppm) and aliphatic carbons (30-60 ppm), respectively. This equation was changed to adapt to our specific copolymer structure resulting from copolymerization of NB and DCPD (eqn (2)):

$$
\frac{I_{\mathrm{sp}^{2}-\mathrm{C}}}{I_{\mathrm{sp}^{3}-\mathrm{C}}}=0.43 \times x_{\mathrm{NB}}+\left(1-x_{\mathrm{NB}}\right) \times \frac{2-x}{3+x}
$$

where 0.43 is the value of the experimental $\frac{I_{\mathrm{sp}^{2}-\mathrm{C}}}{I_{\mathrm{sp}^{3}-\mathrm{C}}}$ in polyNB (calculated from sample NB-100), and $x_{\mathrm{NB}}$ is the molar fraction of NB in the NB/DCPD monomer mixture.

FTIR spectra were recorded with a Nicolet 8700 spectrophotometer (Thermo Scientific) using a mercury cadmium telluride detector. Two modes were used, transmission for monitoring the real-time kinetics of photoROMP in solution and attenuated total reflectance (ATR) for characterization of polymer films. All the spectra were recorded in the range 4000$600 \mathrm{~cm}^{-1}$. The real-time measurements used a scanning velocity of $11.45 \mathrm{~cm} \mathrm{~s}^{-1}$ corresponding to a resolution of $0.964 \mathrm{~cm}^{-1}$. Monomer conversion (Conv.) was determined grounded on the changing of absorption area $A_{t}$ at $1566 \mathrm{~cm}^{-1}(\mathrm{NB}, \mathrm{C}=\mathrm{C}$ stretch), $3047 \mathrm{~cm}^{-1}$ (DCPD, $\mathrm{sp}^{2}=\mathrm{CH}$ ) (eqn (3)):

$$
\text { Conv. }=\frac{A_{t}-A_{0}}{A_{0}} \times 100
$$

where $A_{0}$ and $A_{t}$ are the integrated absorbance of the characteristic vibrational modes before and after UV radiation for $t$ min. To check reproducibility, each experiment was performed at least three times.

\section{Results and discussion}

\section{Study and optimization of the tandem photocatalytic system}

NHC photogeneration and structure of the active ROMP catalyst. There are two possible photochemical pathways to deprotonate the $\mathbf{I M e s H}^{+}$imidazolium cation in $\mathbf{1}$, and thereby to generate the targeted NHC IMes (Scheme 1). Both approaches rely on the photochemistry of tetraphenylborate counter-anion: a direct photolysis of $\mathrm{BPh}_{4}{ }^{-},{ }^{36}$ or a sensitized reaction involving an additional electron acceptor species such as isopropylthioxanthone (ITX). ${ }^{28,29}$ Direct photolysis was carried out by exposure of 1 in THF- $d_{8}(0.03 \mathrm{M})$ to $254 \mathrm{~nm}$, while the sensitized reaction was conducted in similar conditions with a mixture of 1 and ITX (1/1 equiv.) upon irradiation at $365 \mathrm{~nm}$ or $405 \mathrm{~nm}$ (thanks to the higher wavelength absorption of the sensitizer). The precise reaction mechanisms in both cases have been commented on elsewhere..$^{28,29,37,38}$ Table 1 compares the efficiency of the two methods in terms of NHC generated after
Table 1 Effect of excitation wavelength on the release of free $\mathrm{NHC}$ IMes in THF $-d_{8}([1]=0.03 \mathrm{M},[\mathrm{ITX}]=0.03 \mathrm{M})$ after 5 min of irradiation

\begin{tabular}{llll}
\hline Entry & $\begin{array}{l}\text { NHC } \\
\text { photogenerator }\end{array}$ & $\begin{array}{l}\text { Irradiation }_{\text {wavelength }^{a}(\mathrm{~nm})} \\
\text { IMes yield }^{b}(\%)\end{array}$ \\
\hline a & $\mathbf{1}$ & 254 & 11 \\
b & 1/ITX & 365 & 67 \\
c & 1/ITX & 405 & 29
\end{tabular}

${ }^{a}$ Irradiances values: $65 \mathrm{~mW} \mathrm{~cm}{ }^{-2}(365 \mathrm{~nm}), 100 \mathrm{~mW} \mathrm{~cm}^{-2}(405 \mathrm{~nm})$ and $75 \mathrm{~mW} \mathrm{~cm}^{-2}(254 \mathrm{~nm}) .{ }^{b}$ NHC yield was obtained indirectly after addition of 1,3-di- $p$-tolylcarbodiimide (CDI) ([CDI $]=0.03 \mathrm{M}, 1$ equiv.) to the as-irradiated medium. The stable IMes-CDI adduct is formed, which can be precisely quantified by ${ }^{1} \mathrm{H}-\mathrm{NMR} .{ }^{29}$

5 min irradiation. ${ }^{39}$ Clearly, 1 irradiated alone at $254 \mathrm{~nm}$ (entry a) shows less activity in comparison with the combination of $\mathbf{1}$ and ITX at $365 \mathrm{~nm}$ (entry b) and $405 \mathrm{~nm}$ (entry c). Only 11\% IMes was liberated in direct photolysis versus $29 \%(405 \mathrm{~nm})$ and $67 \%(365 \mathrm{~nm})$ in the sensitized reaction. This suggests that the photoinduced route using the 2-component system 1/ITX is more efficient. To account for the poorer NHC yield after the direct photolysis, we rely on the fact that IMes has a nonnegligible absorption band at $254 \mathrm{~nm}\left(\varepsilon_{254}=9.1 \times\right.$ $10^{3} \mathrm{M}^{-1} \mathrm{~cm}^{-1}$ ), while it does not absorb in the UVA range. This could reduce the amount of photons absorbed by $\mathbf{1}$, and undermine the yield of the photolysis reaction. Therefore, the mixture 1/ITX was employed as NHC photogenerator in the rest of the study.

Having proved the aptitude of $\mathbf{1}$ to act as NHC precursor under irradiation (in combination with a sensitizer), we studied the subsequent reaction of IMes with $\left[\operatorname{RuCl}_{2}(p \text {-cymene })\right]_{2}$ dimer Ru-1 to form an active ROMP catalyst..$^{28,29}$ For this, we performed a control experiment in which Ru-1 was reacted with free IMes in THF- $d_{8}$ at room temperature. An orange solution formed spontaneously, and subsequent ${ }^{1} \mathrm{H}-\mathrm{NMR}$ analysis (performed without prior isolation) established that the expected catalyst structure ( $p$-cymene) $\mathrm{RuCl}_{2}$ (IMes) was formed in high yield (see Fig. S1 in ESI $\dagger$ ). The spectrum found was indeed in full agreement with previous literature data ${ }^{\mathbf{4 0}}$ This suggests that Ru-1IMes could be actually the active catalytic species when the tandem system NHC photogenerator/Ru precatalyst is irradiated. However, all attempts to characterize by ${ }^{1} \mathrm{H}-\mathrm{NMR}$ the photogenerated active catalyst have failed, preventing to confirm our hypothesis. The spectra of the catalytic reaction mixture 1/Ru-1/ITX show after irradiation too many signals, preventing the unequivocal identification of the chelated NHCRu complex (see Fig. S2 in ESI†).

Catalyst photolatency. Photochemical latency is a very important characteristic for practical implementation of a photocatalytic system. Consequently, the catalytic activities of Ru-1 (in the presence of ITX, but without 1) has been tested with exclusion of light by using standard ROMP substrates such as $\mathrm{NB}$, and using $\mathrm{CD}_{2} \mathrm{Cl}_{2}$ as a solvent. Results are presented in Table 2. The photochemical latency of Ru-1 was found to be poor since $18 \%$ conversion (entry a) was obtained after $4 \mathrm{~h}$ at room temperature. ROMP could proceed by a decoordination of the $\eta^{6}$-arene ligand to afford a highly unsaturated ruthenium 
Table 2 Photolatency results of Ru dimer/ITX/monomer mixture in $\mathrm{CD}_{2} \mathrm{Cl}_{2}$ ([Monomer] =1 M). All the samples were stored in the dark (Ru dimer $/ \mathrm{ITX} /$ monomer $=1 / 2.5 / 510$ equiv.)

\begin{tabular}{lllcll}
\hline Entry & Precatalyst & Monomer & Reaction time (h) & Conv. $^{a}(\%)$ & $\sigma_{\text {cis }}{ }^{a}$ \\
\hline a & Ru-1 & NB & 4 & 17.6 & 30 \\
b & Ru-1 & ENB & 4 & 0 & n.d \\
c & Ru-2 & NB & 4 & $<1.0$ & n.d \\
d & Ru-2 & NB & 168 & 1.4 & 23 \\
e & Ru-3 & NB & 4 & 90 & 24 \\
$a$ & \\
\multicolumn{7}{l}{ Determined by ${ }^{1}$ H-NMR. } & & &
\end{tabular}

center that evolves into a propagating alkylidene after addition of a NB molecule. ${ }^{41,42}$ In agreement with this hypothesis, no premature reaction took place with ENB (entry b) due to its higher steric hindrance which limits the reaction with the ruthenium center. In the search of other ruthenium precatalysts able to ensure a complete photolatency, Ru-1 was substituted with $\left[\operatorname{RuI}_{2}(p \text {-cymene })\right]_{2}(\mathbf{R u}-2)$ and $\left[\operatorname{RuCl}_{2}(\mathrm{COD})\right]_{2}$ (Ru-3, with COD $=1,5$-cyclooctadiene) to probe separately the effects of the halogen and the ligand in the Ru dimer (see structures in Scheme 2). Remarkably, Ru-2 in the presence of ITX afforded almost no conversion after $4 \mathrm{~h}$ (entry c), and even after $168 \mathrm{~h}$ (entry d). We carefully checked that the addition of 1 to Ru-2/ITX did not increase the conversion, illustrating the minor role played by the NHC precursor in the instability issue. Conversely, the Ru-3 complex exhibited nearly no latency since $90 \%$ conversion was reported after $4 \mathrm{~h}$ (entry e). These results show that the size of the halogen is a crucial parameter affecting the equilibrium for olefin binding. ${ }^{43,44}$ As expected, a larger halogen than chloride such as iodide disfavors olefin binding due to steric hindrance, resulting in a better latency. In all instances, a low content of $c i s$ double bond $\left(\sigma_{\text {cis }}=23-30 \%\right)$ was determined in the polymer structure, which is consistent with the literature data for ROMP relying on ruthenium dimers as catalyst. ${ }^{45,46}$ In conclusion, $\mathbf{R u}-2$ is the best precatalyst candidate.

Photoactivated ROMP in solution. The catalytic activity of the three-component system $\mathrm{Ru}$ precatalyst/1/ITX (1/5/2.5 equiv.) under UV irradiation ( $365 \mathrm{~nm}, 1 \mathrm{~min}$ ) was thus evaluated for the ROMP of NB (Table 3) in $\mathrm{CD}_{2} \mathrm{Cl}_{2}$, using a NMR tube as reaction flask. As expected, the irradiation of a solution devoid of Ru dimer resulted in no reaction (entry a). By contrast, a small conversion was observed when Ru-1 precatalyst was irradiated alone ( $1 \%$, entry b) or in presence of ITX ( $7 \%$, entry c).
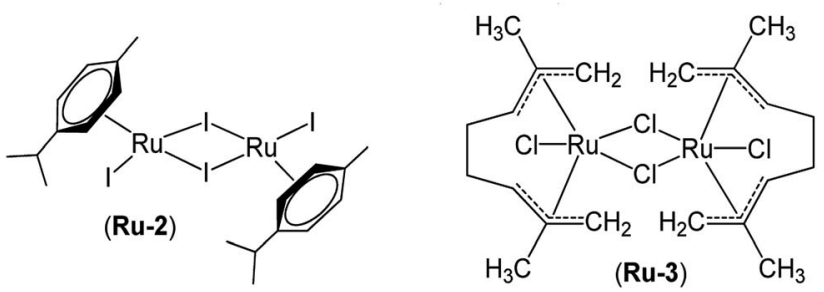

Scheme 2 Chemical structure of alternative ruthenium dimers used as precatalyst.
This result can be reconciled with the poor latency of Ru-1 noted earlier, and suggests that the $\eta^{6}$-arene ligand displacement could be enhanced by a photochemical activation. The vacant site created on the Ru center can form subsequently an active $\mathrm{Ru}$ complex after the addition of a monomer molecule. ${ }^{31,41}$

A much higher catalytic activity was achieved in presence of $\mathbf{1}$ (entry d) with $78 \%$ conversion being reached after $1 \mathrm{~min}$. This suggests the successful formation of a highly active Ru-arene complex, which is likely to be Ru-1-IMes. The content of cis double bond $\left(\sigma_{c i s}=52 \%\right)$ was similar to that obtained with previous systems and supports this assumption. ${ }^{41,47}$ Upon increasing the proportion of ITX from 2.5 equiv. to 5 equiv., a significant increase of conversion was noted (94\%, entry e) which correlates with a higher amount of NHC released and thus of generated Ru-1-IMes. This result is also confirmed by the lower molecular weight $\left(M_{\mathrm{n} \text {-SEC }}\right)$ of the resulting polymer using 5 equiv. of ITX as compared to the one obtained with 2.5 equiv. In contrast, irradiation at $405 \mathrm{~nm}$ instead of $365 \mathrm{~nm}$ led to a much lower conversion ( $22 \%$, entry f). This can be rationalized on the basis of a lower IMes yield at higher excitation wavelength (vide supra). For the polymer produced with the tandem approach precatalyst/NHC (entries $d-f$ ), the molecular weight distributions were monomodal (SEC data), suggesting that only one mechanism is involved in the catalysis. However, high molecular weights $\left(M_{\mathrm{n} \text {-SEC }}\right)$ and rather broad polydispersities $(\theta)$ were obtained, which reflect a poor control of the initiation step. The source of the problem is the ill-defined initiation mechanism and above all, the poor initiation efficiency resulting in only a small number of propagating centers produced in solution. This issue has been widely reported with such class of NHC-coordinated Ru complex. ${ }^{31,32,48,49}$ The effect of the precatalyst structure was also examined. Upon replacing Ru1 by Ru-2, the rate of polymerization slightly decreased (69\%, entry g). By the same reasoning used above to explain latency, it was expected that catalyst activity would decrease from $\mathrm{Cl}$ to I. In this case, there are consequently less backbiting reactions, resulting in polymer with a higher molecular weight and a fairly narrow dispersity index. Ru-3 precatalyst (entry h) led to similar conversions, but the polymer was not soluble in THF, indicating a very high molecular weight polymer and an even lower initiation efficiency. It can be concluded that Ru-1 achieves the best results in terms of NB conversion, but lacks of latency in presence of this monomer. Conversely, Ru-2 exhibits a much better photolatency but at the expense of decreasing reactivity. Our photocatalytic system was also active in the ROMP of ENB. The results are summarized in Table S1. $\dagger$

Mechanism of catalyst activation. As mentioned before, our approach relies on the in situ formation of an active Ru-arene complex from reaction between $\left[\mathrm{RuCl}_{2}(p \text {-cymene })\right]_{2} \mathbf{R u}-\mathbf{1}$ and the photogenerated IMes ligand. However, the presumed NHCcoordinated catalyst Ru-1-IMes identified in this study as the active metathesis catalyst lacks a suitable metal-carbene fragment to initiate ROMP. The literature reports an ill-defined mechanism involving $p$-cymene decoordination and a subsequent reaction between the resultant highly unsaturated ruthenium and a cyclic olefin as being accountable for the formation of active species. ${ }^{31,49}$ This last section questions the 
Table 3 Photopolymerization results of NB using Ru dimer/1/ITX photoinitiating system in $\mathrm{CD}_{2} \mathrm{Cl}_{2}$ ([NB] $=1 \mathrm{M}, 510$ equiv.). Irradiation conditions: $365 \mathrm{~nm}, 6.5 \mathrm{~mW} \mathrm{~cm}^{-2}, 1 \mathrm{~min}$

\begin{tabular}{|c|c|c|c|c|c|c|c|}
\hline Entry & Precatalyst & $\begin{array}{l}\text { Pre-catalyst/1/ITX } \\
\text { (equiv.) }\end{array}$ & Conv. $^{a}(\%)$ & $\sigma_{c i s}^{b}$ & $M_{\mathrm{n}-\mathrm{th}^{c}}\left(\mathrm{~kg} \mathrm{~mol}{ }^{-1}\right)$ & $M_{\mathrm{n}-\mathrm{SEC}}{ }^{d}\left(\mathrm{~kg} \mathrm{\textrm {mol } ^ { - 1 }}\right)$ & $\Xi^{d}$ \\
\hline a & Ru-1 & $0 / 5 / 2.5$ & 0 & n.d & n.d & n.d & n.d \\
\hline c & Ru-1 & $1 / 0 / 2.5$ & 7 & 23 & 1.60 & n.d. & n.d. \\
\hline d & Ru-1 & $1 / 5 / 2.5$ & 78 & 52 & 18.69 & 146.8 & 3.02 \\
\hline $\mathrm{e}$ & Ru-1 & $1 / 5 / 5$ & 94 & 52 & 22.57 & 108.4 & 1.96 \\
\hline $\mathrm{h}$ & Ru-3 & $1 / 5 / 2.5$ & 67 & 48 & 16.10 & n.d. & n.d. \\
\hline
\end{tabular}

${ }^{a}$ Determined by ${ }^{1} \mathrm{H}-\mathrm{NMR} .{ }^{b}$ Calculated from ${ }^{1} \mathrm{H}$-NMR spectrum. ${ }^{c}$ Theoretical number average molar mass $M_{\mathrm{n}-\mathrm{th}}=\mathrm{Conv} . \times \frac{[\mathrm{NB}] \times M_{\mathrm{NB}}}{2 \times[\mathbf{R u}-\mathbf{1}]}$. ${ }^{d}$ Experimental number average molar mass $M_{\mathrm{n} \text {-th }}$ obtained by SEC. ${ }^{e}$ Irradiation at $405 \mathrm{~nm}, 4.7 \mathrm{~mW} \mathrm{~cm}^{-2}, 1 \mathrm{~min}$. n.d. means not determined due to the absence of reaction or the formation of an insoluble polymer.

role(s) played by irradiation $(365 \mathrm{~nm})$ in this mechanism. As established earlier, light has a clear role in the generation of NHC. Bench stability experiments also demonstrate a second role of light in the disengagement of the $\eta^{6}$-arene ligand. To explore other possible effect on polymerization mechanism, NB conversion kinetics was measured in situ by real-time FTIR spectroscopy. For this, the reactive monomer mixture was introduced in a liquid IR cell. IR spectra were acquired continuously during UV exposure (LED spotlight $365 \mathrm{~nm}$ ) in order to construct a conversion-time curve. Fig. 1 shows a typical conversion-time curve while alternating between periods of radiation exposure (white area) and dark (grey area). Surprisingly from the mechanistic hypothesis, a temporal control of polymer chain growth was demonstrated through intermittent exposure of the reaction to UV light since an almost stop of polymerization was observed when light was switched off. This result is in apparent contradiction with the hypothesis of a formation of an active Ru catalyst whose activity could be preserved without irradiation. While almost no conversion occurred in the dark (off periods), polymerization could be reinitiated by re-exposure to light. This has been attributed to

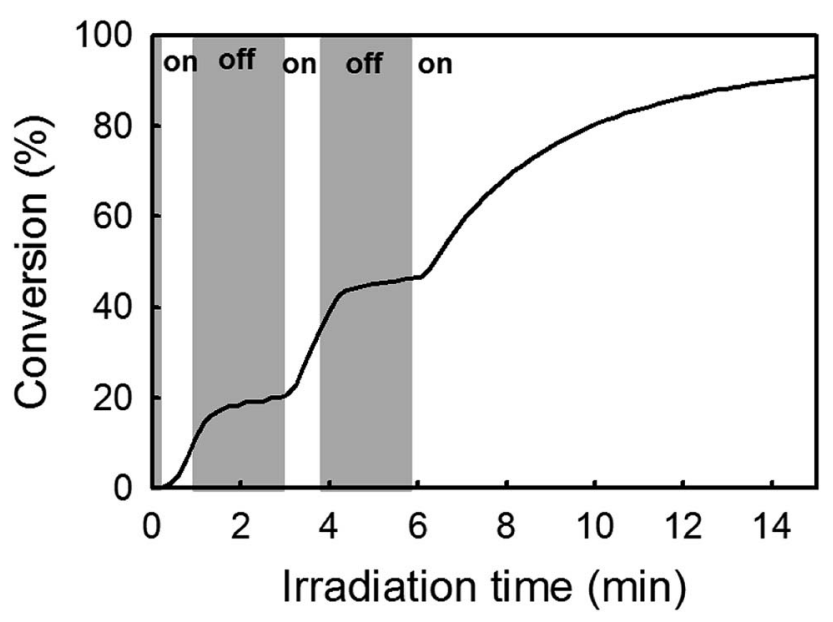

Fig. 1 Conversion-time curve for the ROMP of NB in solution in $\mathrm{CH}_{2} \mathrm{Cl}_{2}$ : light off (grey area), light on (white area). NB/Ru-1/1/ITX = $510 / 1 / 5 / 0.5$ equiv. Irradiation conditions: LED@365 nm, $65 \mathrm{~mW} \mathrm{~cm}{ }^{-2}$. the fact that radiation might promote the multiple insertion of new NB units into the propagating centre..$^{33,41,50}$

Based on this observation, we propose a putative reaction mechanism (Scheme 3) for the ROMP photoinitiation. First, the active complex $\mathrm{RuCl}_{2}$ (arene)(NHC) Ru-1-IMes is subjected to the rapid loss of $p$-cymene ring upon photochemical activation to form an unsaturated Ru species $\mathbf{A} \cdot .^{33,41,50}$ As a subsequent step, the insertion of NB into the metal center occurs to form the Ru complex $\operatorname{RuCl}_{2}(\mathrm{IMes})(\mathrm{NB}) \mathbf{B}$. Then a sigmatropic $[1,2-H]$ rearrangement leads to the formation of a ruthenium-alkylidene complex $\mathbf{C}$ (initiating species). ${ }^{51}$ The next steps follow the typical chain-growth polymerization mechanism involving the metallacyclization and cycloreversion steps, with the particularity that the insertion of new cyclic olefin molecules could be facilitated by light.

\section{Preparation of cross-linked ROMP polymer films}

Scouting experiments. For the preparation of UV-cured films by photoactivated ROMP, emphasis has been made on DCPD because this monomer is able to form a cross-linked structure with high stiffness and impact resistance. ${ }^{52}$ To assess to which extent DCPD could react with our photocatalytic system (Ru-1/1/ ITX), preliminary tests were carried in $\mathrm{CH}_{2} \mathrm{Cl}_{2}$ by monitoring the photopolymerization kinetics using real-time FTIR. Despite its lack of complete latency, Ru-1 was preferred because of its

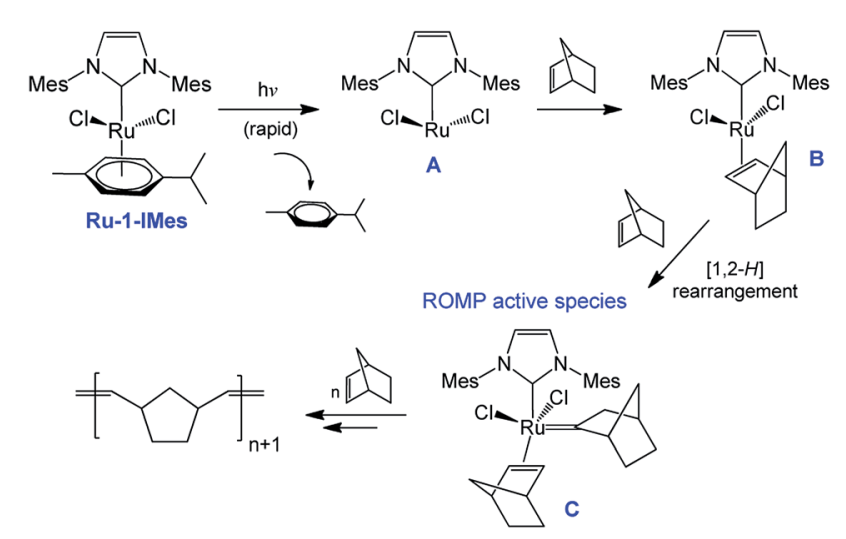

Scheme 3 Proposed photoactivation mechanism of Noels' catalyst. 
higher reactivity. Fig. 2 shows a typical conversion kinetics of DCPD, together with that of NB. As expected, DCPD exhibited a much slower polymerization rate compared to $\mathrm{NB}^{53-55}$ To increase reactivity and achieve a cross-linked structure unattainable with NB only, we proposed a copolymerization of DCPD with NB. ${ }^{13,54}$ As shown on the same plot, a mixture of DCPD/NB $(50 / 50 \mathrm{~mol} \%)$ resulted in intermediate polymerization rates and almost full conversion after 30 min irradiation.

Given the potential of this approach, a range of different (co) polymer films were prepared from a mixture of NB and DCPD (NB-25: 25/75 mol\%; NB-50: 50/50 mol\% and NB-75: 75/ 25 mol\%). For comparison, two control experiments using NB (NB-100) and DCPD (DCPD-100) alone were also performed under similar conditions. As can be seen in Fig. 3, a mixture of monomer and photocatalyst dissolved in $\mathrm{CH}_{2} \mathrm{Cl}_{2}$ was placed in a Teflon mold, covered with a glass slide to avoid solvent or monomer evaporation, and irradiated for $1 \mathrm{~h}$ under a LED panel

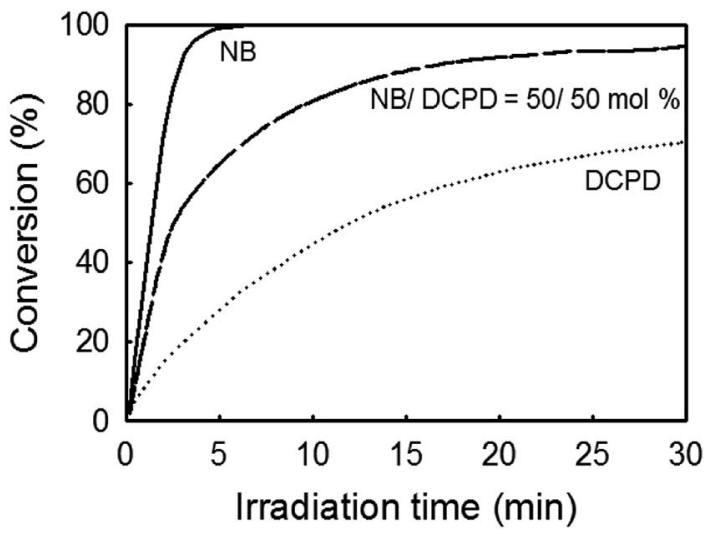

Fig. 2 Photopolymerization kinetic of NB, DCPD and NB/DCPD (50/ 50 mol\%) using photocatalyst system Ru-1/1/ITX in $\mathrm{CH}_{2} \mathrm{Cl}_{2}$ (Monomer/ $\mathrm{Ru}-1 / 1 / \mathrm{ITX}=510 / 1 / 5 / 2.5$ equiv.).
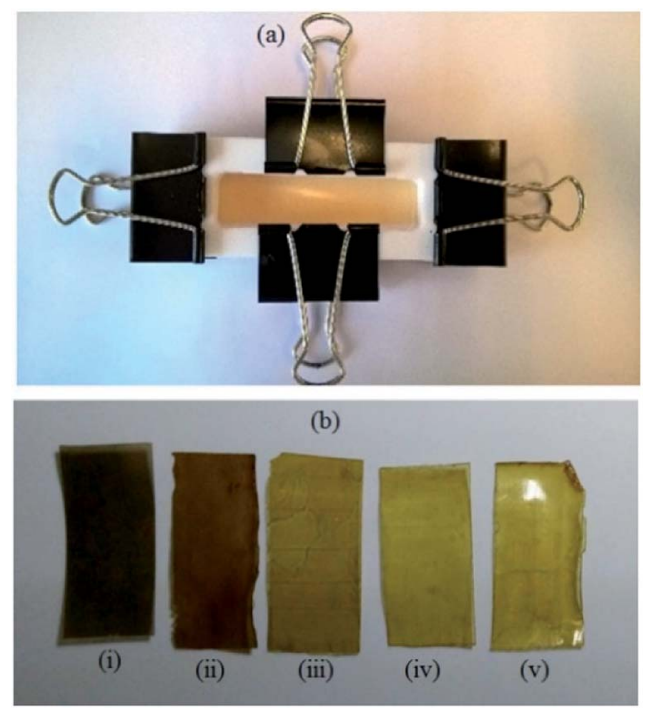

Fig. 3 Photographs of: (a) general set up for the preparation of crosslinked films and (b) polymeric films (i) NB-100, (ii) NB-75, (iii) NB-50, (iv) NB25 and (v) DCPD-100.
(365 $\mathrm{nm}, 5.5 \mathrm{~mW} \mathrm{~cm}^{-2}$ ) in order to reach a high monomer conversion. The swollen polymer films were then dried at ambient conditions, placed under vacuum, then characterized using a range of spectroscopic techniques (FTIR-ATR, ${ }^{13} \mathrm{C} \mathrm{CP}$ MAS), gravimetry, gel content, DSC and TGA. All these techniques are intended to give insight into the structure of the polymer, and in particular the possibility of cross-linking. With regard to this last point, Scheme 4 shows the various possible structures arising from the copolymerization of DCPD with NB. Because the cyclopentene-derived double bond is much less reactive than the norbornenyl double-bond, we assume that the two monomers DCPD and NB could copolymerize first, resulting in the formation of a linear backbone. The cyclopentenederived double bonds can react subsequently to form a crosslinked network. It has been established that the pendant cyclopentene ring from DCPD monomer may react via two possible pathways: ROMP and olefin addition through radical coupling: ${ }^{35,56,57}$

Polymer yield and gel content. Polymer yield and gel contents were determined for the NB/DCPD-based films containing different NB loadings (Fig. 4). As expected, owing to the lower relative reactivity of DCPD compared to that of NB monomer, there is a gradual decrease of the polymer yield at higher concentration in DCPD (Fig. 4a). Indeed, the reaction is almost quantitative for NB-100 (yield $>98 \%$ ) while the yield is minimal for DCPD-100 (50\%). Between these two homopolymers, the hybrid samples display a continuous range of intermediate values. To assess the possible formation of cross-linked network, the gel fraction of the cured specimens was also evaluated. NB-100 film, devoid of DCPD, shows consistently no gel content, in agreement with the formation of linear chains (Fig. 4b). The gel fraction of the films steadily increases with addition of more DCPD, but never reaches $100 \mathrm{wt} \%$. This result proves that our photocatalytic system allows the cross-linking of a fraction of cyclopentene rings. This is in contrast with the $1^{\text {st }}$ generation Grubbs catalysts which are effective only at polymerizing the norbornene ring, thus undermining the production of cross-linked materials. ${ }^{52,58,59}$

FTIR spectroscopy. Turning to chemical structure of the polymer network, the same series of five films was analyzed by ATR-FTIR spectroscopy. In Fig. 5A, all spectra show the absence of signal at $1566 \mathrm{~cm}^{-1}$ ascribed to the alkene $\mathrm{C}=\mathrm{C}$ stretching vibration of norbornenyl groups (present indistinctly in NB or DCPD). ${ }^{28,60}$ This suggests that norbornenyl rings were either completely reacted during the ROMP or removed upon drying

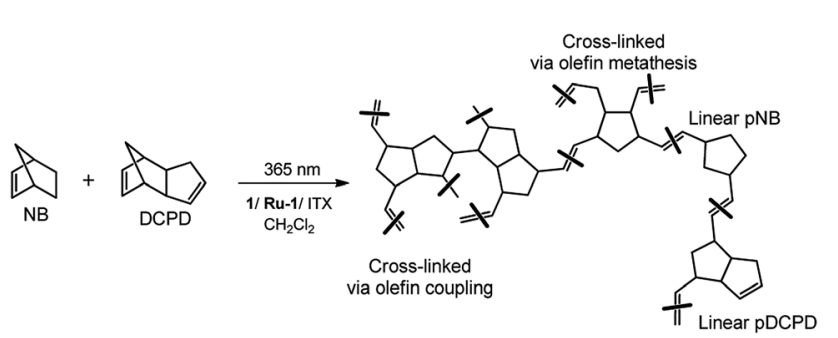

Scheme 4 Set of chemical structures arising from a ROM copolymerization of NB and DCPD. 

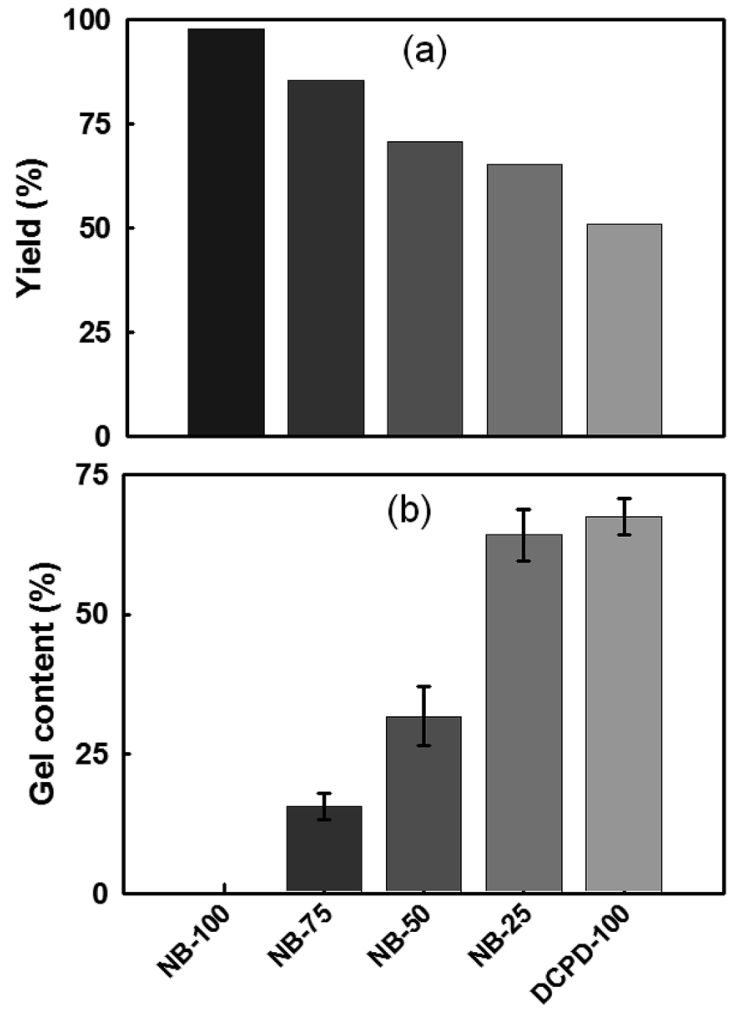

Fig. 4 Characterization of UV-irradiated NB/DCPD specimens: (a) polymer yield, and (b) gel content.

(unreacted monomer). Because cyclopentene has a lower ring strain than $\mathrm{NB}$, the frequency of the $\mathrm{C}=\mathrm{C}$ stretching vibration is decreased and generally arises at $1610-1650 \mathrm{~cm}^{-1}$. The $\nu(\mathrm{C}=\mathrm{C})$ of the internal double bond of cyclopentene (which is anyway a weakly intense band) is not visible in our system regardless of DCPD content. To estimate the amount of residual cyclopentene rings, the specific out-of-plane deformation vibration at $\sim 710 \mathrm{~cm}^{-1}$ was considered. Clearly visible at $708 \mathrm{~cm}^{-1}$, its presence supports an incomplete cross-linking process. ${ }^{57}$ In addition, the signals at $970 \mathrm{~cm}^{-1}$ and $754 \mathrm{~cm}^{-1}$ were attributed to the deformation vibrations of $=\mathrm{C}-\mathrm{H}$ bonds on trans and cis acyclic double bonds, respectively. ${ }^{57,61}$ They indicate that the chain backbone is made up of a mixture of both trans- and cisdisubstituted alkene $-(\mathrm{CH}=\mathrm{CH})$ - in accordance with a ROMP mechanism. The $=\mathrm{C}-\mathrm{H}$ stretching region at $3000-3100 \mathrm{~cm}^{-1}$ is also informative because it is not overlapped by alkane $\mathrm{C}-\mathrm{H}$ stretching absorption occurring below $3000 \mathrm{~cm}^{-1}$. As shown in Fig. 5B, two broad signals at $3047 \mathrm{~cm}^{-1}$ and $3002 \mathrm{~cm}^{-1}$ were found in the spectra of polymer films containing DCPD, that are readily ascribed to the $=\mathrm{C}-\mathrm{H}$ stretching of $-\mathrm{CH}=\mathrm{CH}$ - vinylene groups. The band at $3047 \mathrm{~cm}^{-1}$ can be associated to cyclic olefins (residual cyclopentene) while the second signal at $3002 \mathrm{~cm}^{-1}$ reflects acyclic olefin (cyclopentene reacted by ROMP). ${ }^{35,60,62}$ In conclusion, the FTIR data of DCPD-based films show a partial cross-linking by reaction of the cyclopentene ring, which occurs through a metathesis mechanism. The possibility of cross-linking via olefin coupling of the

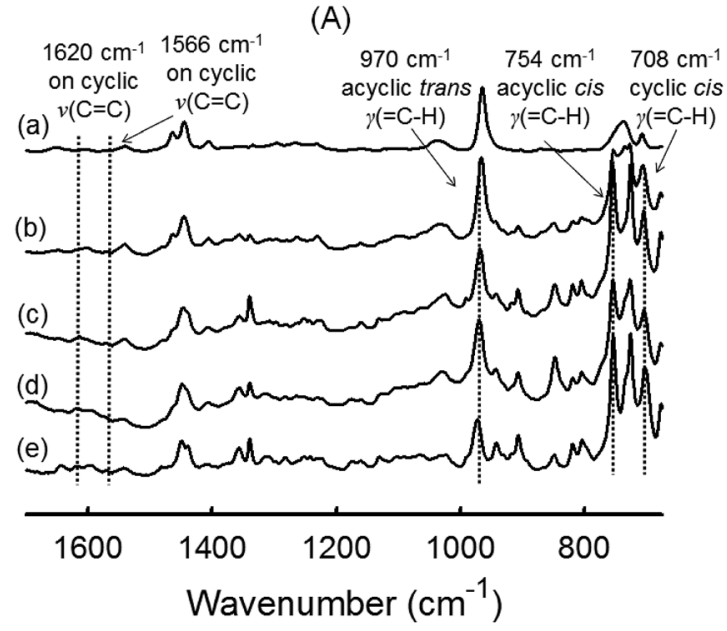

(B)

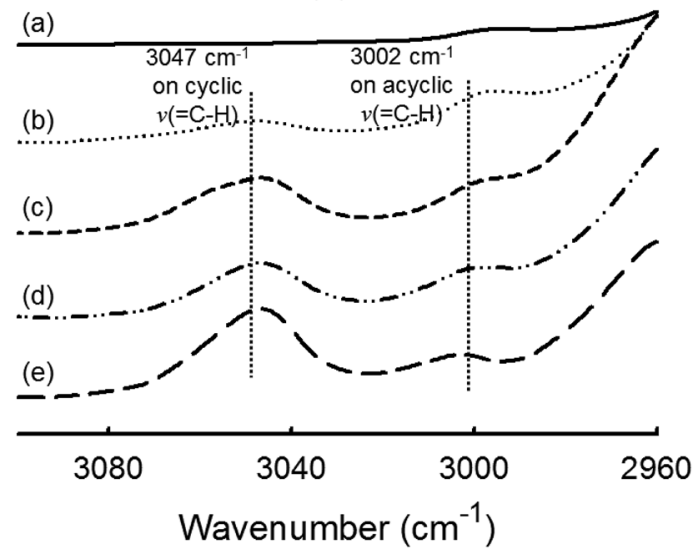

Fig. 5 FTIR-ATR spectra of polymer films obtained by photoROMP at 365 nm: (a) NB-100, (b) NB-75, (c) NB-50, (d) NB-25 and (e) DCPD100: (A) expanded spectra in a range of $675-1700 \mathrm{~cm}^{-1}$ and (B) expanded spectra in a range of $2960-3100 \mathrm{~cm}^{-1}$.

cyclopentene ring is examined in the next section that deals with the use of ${ }^{13} \mathrm{C}$ solid state NMR to characterize the polymer films.

${ }^{13} \mathrm{C}$ CP MAS NMR. In Fig. 6 , the ${ }^{13} \mathrm{C}$ CP MAS spectra of the different NB/DCPD samples display strong similarities. The region at $\sim 130 \mathrm{ppm}$ represents olefinic carbons $\left(\mathrm{sp}^{2}-\mathrm{C}\right)$ while the signals at 30-60 ppm are reflective of aliphatic carbons $\left(\mathrm{sp}^{3}\right.$ $\mathrm{C}$ ). As mentioned above (Scheme 4 ), the $\mathrm{C}=\mathrm{C}$ double bonds of cyclopentene ring can undergo either metathesis or olefin coupling reactions. Of interest is that ${ }^{13} \mathrm{C}$ CP MAS NMR can be used to estimate the contribution of olefin coupling. Indeed, occurrence of olefin coupling is manifested by the conversion of two $\mathrm{sp}^{2}$ carbons (from cyclopentene) into two $\mathrm{sp}^{3}$ carbons. Consequently, the ratio of integrated area of $\mathrm{sp}^{2}-\mathrm{C}$ and $\mathrm{sp}^{3}-\mathrm{C}$ can give access to the fraction of cyclopentene involved in olefin coupling (see Experimental section for calculation details). ${ }^{35,63}$ Our calculations reveal a significant contribution of olefin coupling which ranges from 11 to $34 \%$. Olefin coupling of cyclopentene ring tends to increase with a higher concentration of NB: $11 \%$ (DCPD-100) <22\% (NB-25) <26\% (NB-50) <34\% (NB- 


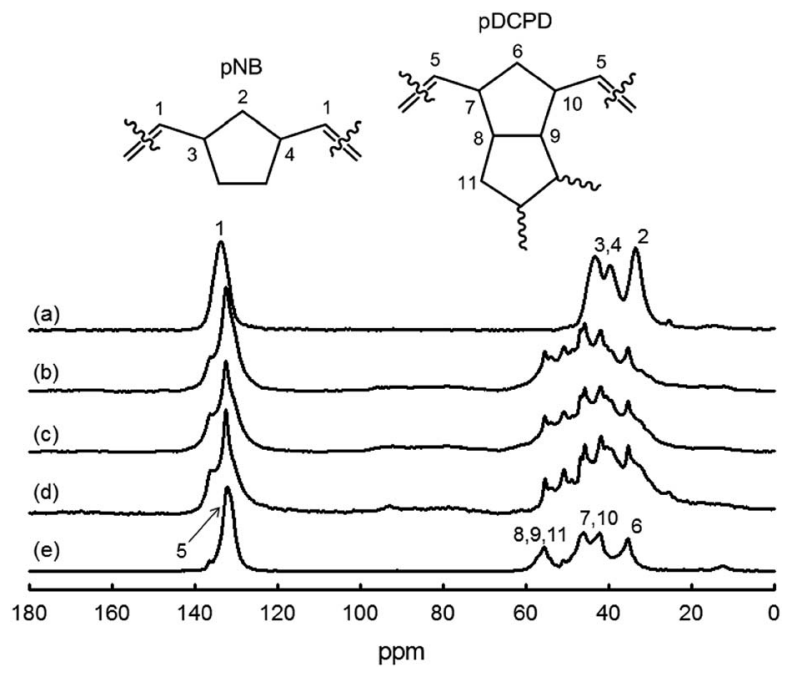

Fig. $6{ }^{13}$ C CP MAS NMR spectra of NB/DCPB films: (a) NB-100, (b) NB75, (c) NB-50, (d) NB-25 and (e) DCPD-100.

75). This trend can be rationalized on the basis that ROMP of $\mathrm{NB}$ is known to be highly exothermic and that olefin coupling is activated by heat. ${ }^{56}$

Thermal analysis. The same series of NB/DCPD-based specimens was analyzed by DSC and TGA under $\mathrm{N}_{2}$. As shown in Fig. 7A, the DSC thermograms indicate a strong impact of DCPD content on the glass transition temperature $\left(T_{\mathrm{g}}\right)$. As expected, the lowest $T_{\mathrm{g}}$ value was found for pure polyNB (NB-100); the value of $27^{\circ} \mathrm{C}$ is fully consistent with literature data. ${ }^{64,65}$ Upon increasing the content of DCPD, higher $T_{\mathrm{g}}$ values were gradually obtained, with a maximum at $114{ }^{\circ} \mathrm{C}$ found for DCPD-100. This tendency is likely to be caused by the increase of cross-linking density as more cyclopentene rings react. In the literature, the $T_{\mathrm{g}}$ of polyDCPD generally ranges from $53-165{ }^{\circ} \mathrm{C} .{ }^{52,53}$ Hence, our intermediate $T_{\mathrm{g}}$ value agrees with a significant fraction of non-reacted cyclopentene rings as evidenced by FTIR and solid-state NMR. The TGA traces in Fig. 7B are much less dependent on the DCPD concentration and show systematically two distinct decomposition regions. The gradual weight loss during the first decomposition stage arising at $200{ }^{\circ} \mathrm{C}$ is suggestive of lowmolecular weight chains decomposition. Because of its sluggish polymerization rates, pure polyDCPD is likely to contain a higher fraction of short linear chains. This drives a weight loss at low temperature that is significantly more marked than for NB-samples. During the second decomposition stage taking place at $400-500{ }^{\circ} \mathrm{C}$, all curves exhibited a serious decline in the weight loss, illustrating the degradation of the main polymer chains. ${ }^{52,66}$ DCPD-100 showed the greatest thermal stability whereas a slight and progressive decrease was noted upon increasing NB loading. This is consistent with the drop of cross-linking density. ${ }^{66}$ Also noteworthy is that a single main decomposition peak is observed regardless of NB content, suggesting a good homogeneity of the copolymer network. All samples left a charcoal residue, the highest amount (23\%) was achieved with DCPD-100.
(A)

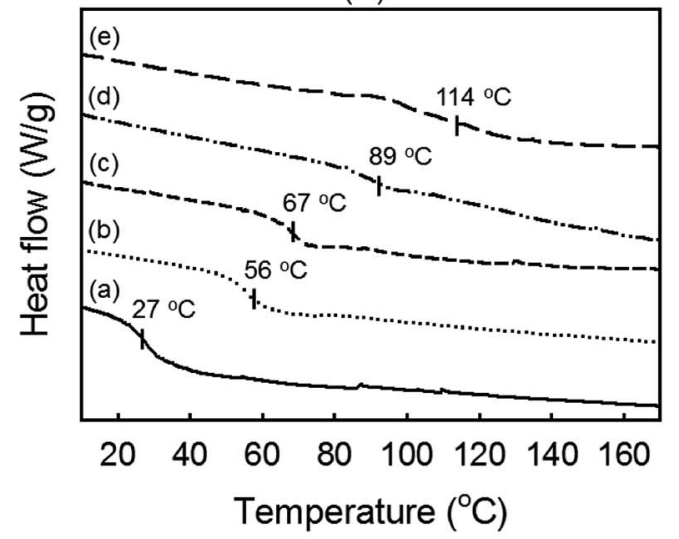

(B)

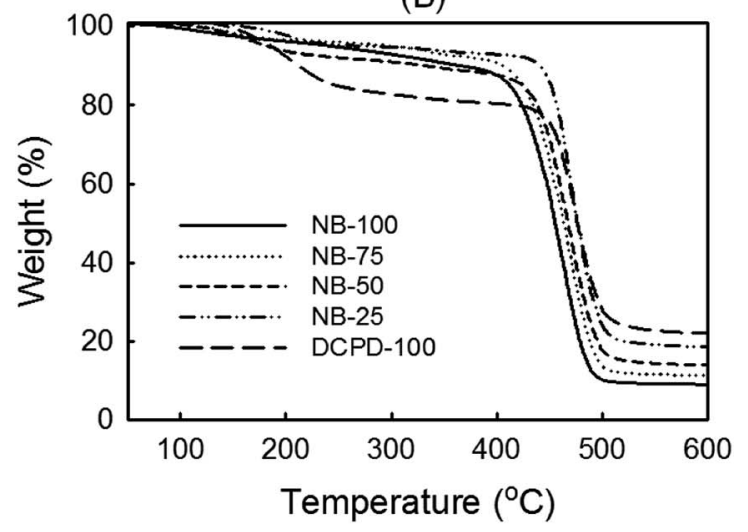

Fig. 7 Thermal characterization of NB/DCPD samples performed under nitrogen environment NB-100 (a), NB-75 (b), NB-50 (c), NB-25 (d) and DCPD-100 (e). (A) DSC traces and (B) TGA thermograms.

\section{Conclusions}

We have demonstrated that cross-linked ROMP polymer films can be produced under UV irradiation through the copolymerization of NB with DCPD. The approach for photoactivated olefin metathesis used a NHC photogenerator (1/ITX) combined with an inactive Ru precatalyst (Ru-1, Ru-2 and Ru-3). An active NHC-coordinated Ru-arene complex was presumed to form by reaction between the ruthenium precatalyst and the photogenerated NHC IMes. Irradiation at $365 \mathrm{~nm}$ was also proved to have a critical role in the formation of the active metathesis species by promoting the decoordination of the $p$-cymene ligand and the multiple insertions of new NB units into the propagating centre. The films were homogeneous, and the possibility of cross-linking was attested by the measurement of gel contents $(10-70 \%)$ and the rising of $T_{\mathrm{g}}$ value when increasing DCPD loading. FTIR data showed a complete conversion of norbornenyl group in both monomers, but an incomplete ring-opening of the cyclopentene pendant group from DCPD. This lower ring-strained cyclic olefin is subjected to metathesis but also to olefin coupling reactions as evidenced by ${ }^{13} \mathrm{C}$ solid-state NMR. We anticipate that photoROMP of NB and DCPD derivatives will enable the development of new crosslinked coatings with chemical, thermal and mechanical 
properties currently not attainable with conventional radical photopolymerization.

\section{Conflicts of interest}

There are no conflicts to declare.

\section{Acknowledgements}

Financial support by French National Research Agency (ANR program: DS0304 2016, contract number: ANR-16-CE07-0016) is gratefully acknowledged. We are grateful to Dr Olivier Soppera, Dr Julien Poly, Dr Aissam Airoudj and Mr Stephan Knopf for their support in analysis of results.

\section{Notes and references}

1 J. B. Matson and R. H. Grubbs, J. Am. Chem. Soc., 2008, 130, 6731-6733.

2 X. Bantreil and S. P. Nolan, Nat. Protoc., 2011, 6, 69-77.

3 K. J. Arrington, J. B. Waugh, S. C. Radzinski and J. B. Matson, Macromolecules, 2017, 50, 4180-4187.

4 P. Schwab, M. B. France, J. W. Ziller and R. H. Grubbs, Angew. Chem., Int. Ed., 1995, 34, 2039-2041.

5 R. R. Schrock, J. S. Murdzek, G. C. Bazan, J. Robbins, M. DiMare and M. O'Regan, J. Am. Chem. Soc., 1990, 112, 3875-3886.

6 M. Scholl, S. Ding, C. W. Lee and R. H. Grubbs, Org. Lett., 1999, 1, 953-956.

7 J. Huang, E. D. Stevens, S. P. Nolan and J. L. Petersen, J. Am. Chem. Soc., 1999, 121, 2674-2678.

8 S. B. Garber, J. S. Kingsbury, B. L. Gray and A. H. Hoveyda, J. Am. Chem. Soc., 2000, 122, 8168-8179.

9 C. W. Bielawski and R. H. Grubbs, Angew. Chem., Int. Ed., 2000, 39, 2903-2906.

10 W. A. Green, J. Mol. Catal. A: Chem., 2004, 213, 39-45.

11 Z. Yao, L. Zhou, B. Dai and K. Cao, J. Appl. Polym. Sci., 2012, 125, 2489-2493.

12 J. Asrar, J. Appl. Polym. Sci., 1993, 47, 289-293.

13 A. E. Goetz and A. J. Boydston, J. Am. Chem. Soc., 2015, 137, $7572-7575$.

14 A. Ben-Asuly, E. Tzur, C. E. Diesendruck, M. Sigalov, I. Goldberg and N. G. Lemcoff, Organometallics, 2008, 27, 811-813.

15 C. Slugovc, D. Burtscher, F. Stelzer and K. Mereiter, Organometallics, 2005, 24, 2255-2258.

16 M. Barbasiewicz, A. Szadkowska, R. Bujok and K. Grela, Organometallics, 2006, 25, 3599-3604.

17 A. Piermattei, S. Karthikeyan and R. P. Sijbesma, Nat. Chem., 2009, 1, 133-137.

18 A. Ben-Asuly, A. Aharoni, C. E. Diesendruck, Y. Vidavsky, I. Goldberg, B. F. Straub and N. G. Lemcoff, Organometallics, 2009, 28, 4652-4655.

19 A. Aharoni, Y. Vidavsky, C. E. Diesendruck, A. Ben-Asuly, I. Goldberg and N. G. Lemcoff, Organometallics, 2011, 30, 1607-1615.
20 Y. Ginzburg, A. Anaby, Y. Vidavsky, C. E. Diesendruck, A. Ben-Asuly, I. Goldberg and N. G. Lemcoff, Organometallics, 2011, 30, 3430-3437.

21 B. K. Keitz and R. H. Grubbs, J. Am. Chem. Soc., 2009, 131, 2038-2039.

22 A. Y. Khalimon, E. M. Leitao and W. E. Piers, Organometallics, 2012, 31, 5634-5637.

23 C. Theunissen, M. A. Ashley and T. Rovis, J. Am. Chem. Soc., 2019, 141, 6791-6796.

24 O. Eivgi and N. Lemcoff, Synthesis, 2018, 50, 49-63.

25 R. A. Weitekamp, H. A. Atwater and R. H. Grubbs, J. Am. Chem. Soc., 2013, 135, 16817-16820.

26 D. Wang, K. Wurst, W. Knolle, U. Decker, L. Prager, S. Naumov and M. R. Buchmeiser, Angew. Chem., Int. Ed., 2008, 47, 3267-3270.

27 D. Wang, K. Wurst and M. R. Buchmeiser, Chem.-Eur. J., 2010, 16, 12928-12934.

28 J. Pinaud, T. K. H. Trinh, D. Sauvanier, E. Placet, S. Songsee, P. Lacroix-Desmazes, J.-M. Becht, B. Tarablsi, J. Lalevée, L. Pichavant, V. Héroguez and A. Chemtob, Chem.-Eur. J., 2018, 24, 337-341.

29 T. K. H. Trinh, J.-P. Malval, F. Morlet-Savary, J. Pinaud, P. Lacroix-Desmazes, C. Reibel, V. Héroguez and A. Chemtob, Chem.-Eur. J., 2019, 25, 9242-9252.

30 W. A. Herrmann, M. Elison, J. Fischer, C. Köcher and G. R. J. Artus, Chem.-Eur. J., 1996, 2, 772-780.

31 A. Tudose, A. Demonceau and L. Delaude, J. Organomet. Chem., 2006, 691, 5356-5365.

32 L. Delaude, M. Szypa, A. Demonceau and A. F. Noels, Adv. Synth. Catal., 2002, 344, 749.

33 L. Delaude, A. Demonceau and A. F. Noels, Chem. Commun., 2001, 986-987.

34 D. Massiot, F. Fayon, M. Capron, I. King, S. L. Calvé, B. Alonso, J.-O. Durand, B. Bujoli, Z. Gan and G. Hoatson, Magn. Reson. Chem., 2002, 40, 70-76.

35 D. P. Mohite, S. Mahadik-Khanolkar, H. Luo, H. Lu, C. Sotiriou-Leventis and N. Leventis, Soft Matter, 2013, 9, 1516-1530.

36 J. D. Wilkey and G. B. Schuster, J. Org. Chem., 1987, 52, 21172122.

37 X. Sun, J. P. Gao and Z. Y. Wang, J. Am. Chem. Soc., 2008, 130, 8130-8131.

38 X. Sun, Development of tetraphenylborate-based photobase generators and sacrificial polycarbonates for radiation curing and photoresist applications, PhD thesis, Carleton University, 2009.

39 A. V. Zhukhovitskiy, J. Geng and J. A. Johnson, Chem.-Eur. J., 2015, 21, 5685-5688.

40 L. Jafarpour, J. Huang, E. D. Stevens and S. P. Nolan, Organometallics, 1999, 18, 3760-3763.

41 Y. Zhang, D. Wang, P. Lönnecke, T. Scherzer and M. R. Buchmeiser, Macromol. Symp., 2006, 236, 30-37.

42 A. Hafner, A. Mühlebach and P. A. van der Schaaf, Angew. Chem., Int. Ed., 1997, 36, 2121-2124.

43 E. L. Dias, S. T. Nguyen and R. H. Grubbs, J. Am. Chem. Soc., 1997, 119, 3887-3897. 
44 M. S. Sanford, J. A. Love and R. H. Grubbs, J. Am. Chem. Soc., 2001, 123, 6543-6554.

45 L. Delaude, A. Demonceau and A. F. Noels, Macromolecules, 2003, 36, 1446-1456.

46 A. Demonceau, A. F. Noels, E. Saive and A. J. Hubert, J. Mol. Catal., 1992, 76, 123-132.

47 L. Delaude, A. Demonceau and A. F. Noels, Curr. Org. Chem., 2006, 10, 203-215.

48 M. Ahr, C. Thieuleux, C. Copéret, B. Fenet and J.-M. Basset, Adv. Synth. Catal., 2007, 349, 1587-1591.

49 P. Alvarez, J. Gimeno and E. Lastra, Organometallics, 2002, 21, 5678-5680.

50 C. S. Day and D. E. Fogg, Organometallics, 2018, 37, 45514555.

51 D. Wang, J. Unold, M. Bubrin, W. Frey, W. Kaim and M. R. Buchmeiser, ChemCatChem, 2012, 4, 1808-1812.

52 S. Saha, Y. Ginzburg, I. Rozenberg, O. Iliashevsky, A. BenAsuly and N. Gabriel Lemcoff, Polym. Chem., 2016, 7, 30713075.

53 J. Chen, F. P. Burns, M. G. Moffitt and J. E. Wulff, ACS Omega, 2016, 1, 532-540.

54 G. Yang, T. C. Mauldin and J. K. Lee, $R S C A d v ., 2015,5$, 59120-59130.

55 K. Nomura and X. Hou, Dalton Trans., 2016, 46, 12-24.
56 T. A. Davidson, K. B. Wagener and D. B. Priddy, Macromolecules, 1996, 29, 786-788.

57 G. Raptopoulos, G. C. Anyfantis, D. Chriti and P. Paraskevopoulou, Inorg. Chim. Acta, 2017, 460, 69-76.

58 S. J. Cantrill, R. H. Grubbs, D. Lanari, K. C.-F. Leung, A. Nelson, K. G. Poulin-Kerstien, S. P. Smidt, J. F. Stoddart and D. A. Tirrell, Org. Lett., 2005, 7, 4213-4216.

59 L. Gong, K. Liu, E. Ou, F. Xu, Y. Lu, Z. Wang, T. Gao, Z. Yang and W. Xu, RSC Adv., 2015, 5, 26185-26188.

60 Q. Sun, S. Ma, Z. Ge and Y. Luo, High Perform. Polym., 2017, 29, 931-936.

61 M. J. Abadie, M. Dimonie, C. Couve and V. Dragutan, Eur. Polym. J., 2000, 36, 1213-1219.

62 S. Saha, Y. Ginzburg, I. Rozenberg, O. Iliashevsky, A. BenAsuly and N. Gabriel Lemcoff, Polym. Chem., 2016, 7, 30713075 .

63 A. Bang, D. Mohite, A. M. Saeed, N. Leventis and C. SotiriouLeventis, J. Sol-Gel Sci. Technol., 2015, 75, 460-474.

64 R. F. Ohm and T. M. Vial, J. Elastomers Plast., 1978, 10, 150162.

65 A. M. Spring, D. Maeda, M. Ozawa, K. Odoi, F. Qiu, K. Yamamoto and S. Yokoyama, Polym. Bull., 2015, 72, 503-521.

66 M. R. Kessler and S. R. White, J. Polym. Sci., Part A: Polym. Chem., 2002, 40, 2373-2383. 